\title{
Synthesis and Characterization of Substituted Metal(II)-octa- Methoxyphenyllmino Phthalocyanine Pigments
}

\author{
FASIULLA $^{1 *}$ and M. P.YASHODA ${ }^{1}$ \\ 'Department of Chemistry, Manipal Institute of Technology, Manipal, Udupi district, Karnataka, India. \\ 'Department of Chemistry, MIT, Manipal, Udupi District, Karnataka, India. \\ ${ }^{*}$ Corresponding author E-mail: fasiulla1976@gmail.com \\ http://dx.doi.org/10.13005/ojc/330548
}

(Received: April 20, 2017; Accepted: June 28, 2017)

\begin{abstract}
The synthesis, spectral and magnetic susceptibility on symmetrically substituted metal (II)-octa-methoxyphenyl imino phthalocyanine by condensing octa amino phthalocyanines with o-anisaldehyde are described. The dark green colour octa amino phthalocyanine derivatives were characterized by electronic, IR, elemental analysis, magnetic susceptibility, powder X-ray diffraction and thermo gravimetric analysis (TGA) studies to structural integrity, check the purity and crystalline properties of the pigments. The variation of magnetic moment as function of field strength 2.20 to $4.01 \mathrm{~kg}$ indicated the presence of intermolecular co-operative effect
\end{abstract}

Keywords: Octamethoxy imino phathalocynaine, Electronic, IR, XRD, Magnetic susceptibility, TGA.

\section{INTRODUCTION}

Phthalocyanines ( $\mathrm{Pc}$ ) have been worldwide focused on attention to explore and exploit the various versatile chromophores. Phthalocyanines are blue or green in color have been widely exploited as colorants. Phthalocyanines have a strong optical absorbance in the red and near-IR portions of the electromagnetic spectrum and are stable under a wide range of thermal and electrochemical conditions. Besides the optical properties and stability of phthalocyanines, these dyes must be evaluated with regard to their electrochemical suitability and structural suitability for a given application such as an electronic material.

Phthalocyanines like high tinctorial property for use as pigments for printing inks, plastics, rubbers, roofing granules, leather, gasoline and photographic colour printing, fastness to the light, chemical inertness etc. The electro-optic behavior has led to their use in xerography. Phthalocyanines have also been investigated for potential use in a variety of other applications including nonlinear optical generation and 
limiting,photodynamic therapy, photovoltaics, sensors, electrochromic displays and information storage.Solubility and various physico-chemical properties associated with metal phthalocyanines primarily depend upon the central metal atom and nature as well as the position of the periphery of the molecule.

In the present paper discussesthe synthesis and spectral and magnetic susceptibility on substituted metal (II) 1, 3, 8, 10, 15, 17, 22, 24- ocat methoxyphenyl imino phthalocyanines. The lite- rature survey revealed about the reports on synthesis spectral and magnetic susceptibility on substituted (II) octaamino phthalocyanines. The available procedure in the literature was suitably modified and used for the synthetic route. The substituted metal(II)octa-methoxyphenyl imino phthalocyanines pigments is given as per the scheme-1.

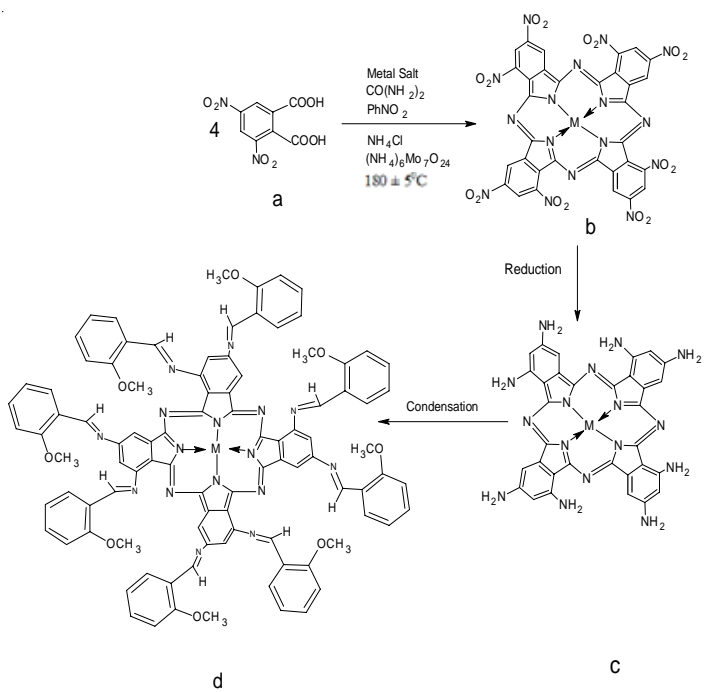

Scheme.1. Synthesis of metal (II) - octa-methoxy phenyl iminophthalocyanine.a. 3, 5-dinitrophthalic acid, b. M-PcONc. M-PcOAand d. M-MePhImPcO

The elemental analysis Carbon, Hydrogen, and Nitrogen were performed at Cochin University, Sophisticated Test \& Instrumentation Center, Kochi, Kerala, India. The metal content was determined by incinerating them to the oxides. The magnetic susceptibility is carried out at room temperature ( 3 supply unit and a digital semimicrobalance. The diamagnetic corrections to be calculate using Pascal's constant. The calibrantmercury tetra thiocyanato cobalt (II) complex was used. Shimadzu UV-Vis spectra recorded spectrophotometer. Infrared spectra were measured using Nicolet MX-FTIR spectrometer with $\mathrm{KBr}$ pellets. Philips analytical PW-1710 X-ray diffractrometer was used to study the diffraction pattern. The spectra were recorded using $\mathrm{Cu} \mathrm{Ka}$ as target material, a current of $20 \mathrm{~mA}$, at the voltage of $40 \mathrm{kV}$, a channel width of $7 \mathrm{~mm}, \mathrm{~A}$ time constant of 4 , and chart speed of $10 \mathrm{~mm} / \mathrm{min}$. Thermo-gravimetric analyses were carried out by using a Shimadzu DTG/DTA-60. The TGA and DTA is thermal analyzer at a heating rate of $10^{\circ} \mathrm{C} / \mathrm{min}$. in a nitrogen atmosphere and air.

\section{EXPERIMENTAL}

The 3,5-dintrophthalic acid was prepared as reported elsewhere. All necessary chemicals used in the experiment were of analytical grade obtained from commercial supplier. The substituted metal (II) 1, 3, 8, 10, 15, 17, 22, 24-octa amino phthalocyanines complexe sprepared by the reported procedure. These octa amino phthalocyanines complexes converted into imino phthalocyanines complexes by using 2-methoxy aldehyde compounds with suitable modification as per scheme-1

\section{Preparation of Copper (II) octa- methoxyphenylimino} phthalocyanines complex.

Copper (II), 1, 3, 8, 10, 15, 17, 22, 24- octanitro phthalocyanine complex was synthesized according to reported elsewhere. The nitro derivative of the aforesaid complex was converted into amino derivative quantitatively by reduction using sodium sulphide nonahydrate $\left(\mathrm{Na}_{2} \mathrm{~S} 9 \mathrm{H}_{2} \mathrm{O}\right)$ in aqueous medium. The finely grounded metal (II) -octa amino phthalocyanine (6.30g / 0.1mole) was added in stiochiometric quantity of $15 \mathrm{M}$ sulphuric acid, to this $(13.6 \mathrm{~g} / 0.1 \mathrm{~mole}) 2$-methoxy benzaldehyde is dissolved in ethyl alcohol and catalytic amount of con. $\mathrm{H}_{2} \mathrm{SO}_{4}$ was added, and the contents were refluxed with stirring for about 5 hours.

The settled green solid condensed octa-methoxyphenylimino phthalocyanine complex was washed alternatively twice with alcohol free from aldehyde and finally it was washed with 
distilled water. The complexes dried at $100^{\circ} \mathrm{C}$ for $40 \mathrm{~min}$. and finally in a vacuum over anhydrous phosphorous pentoxide. CoMePhlmPcO, NiMe PhlmPcO, ZnMePhImPcO, were synthesized similarly by using the respective substituted metal aminophthalocyanines.

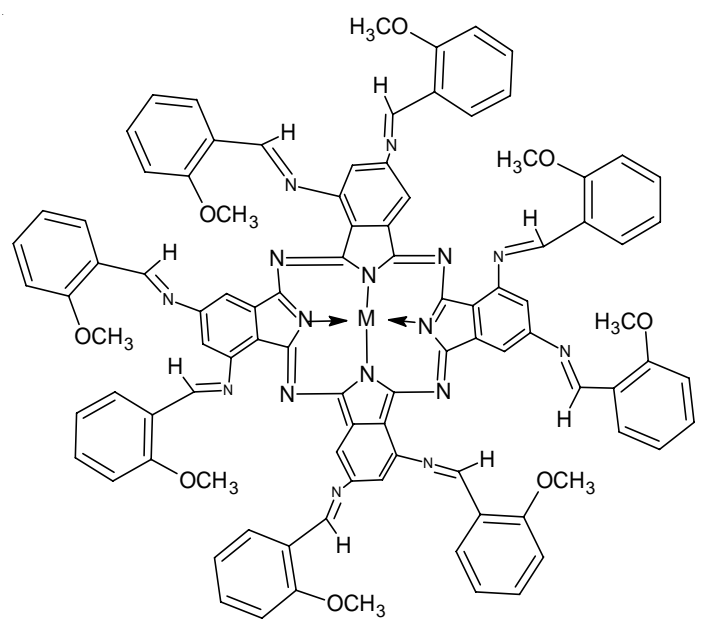

Fig.1. Suggested structure of symmetrically substituted octa-methoxyphenylimino phthalocyanines, where $\mathrm{M}=\mathrm{Co}, \mathrm{Cu}, \mathrm{Ni}$, and $\mathrm{Zn}$.

\section{RESULTS AND DISCUSSION}

The synthesis of M-MePhlmPcO yield pure complexes and it shows that dark green in color except for that of zinc, green with brown tinge. These complexes are sparingly inDimethyl sulfoxide, Dimethylformamide, pyridine and completely soluble in con. $\mathrm{H}_{2} \mathrm{SO}_{4}$. The elemental analysis results are given in Table. 1 and the calculated values and are consistent with the suggested structure given below in Fig.1. The reduction of nitro derivatives to the corresponding amino derivatives and the conversion of later into M-MePhImPcO's were almost quantitative with good yield.

\section{Electronic Spectra}

The synthesized complexes were recorded DMSO in the concentration range of $1.00-1.40 \times 10^{-4} \mathrm{M}$ and data are summarized in Table 2. All the absorption peaks are interpreted in terms of Q- band, B-band, L-band and C-band characteristic of phthalocyanine molecule. $\mathrm{M}-\mathrm{Me} \mathrm{Phlm} \mathrm{PcO}$ complexes a peak were observed in the wave length $726-749 \mathrm{~nm}$, which was assigned to Q-band, $\mathrm{a}_{1 \mathrm{u}} \rightarrow \mathrm{e}_{\mathrm{g}}$ transition and 327-337 $\mathrm{nm}$ assigned to $\mathrm{B}-$ band due to $\mathrm{a}_{2 \mathrm{u}} \rightarrow \mathrm{e}_{\mathrm{g}}$ transition. The

Table.1: Elemental analysis and magnetic susceptibility data of metal (II) -octamethoxyphenyliminophthalocyanines.

\begin{tabular}{|c|c|c|c|c|c|}
\hline $\begin{array}{l}\text { Complex } \\
\text { (Yield) } \\
\text { Colour }\end{array}$ & $\begin{array}{l}\text { Empirical } \\
\text { formulae. } \\
\text { (Formula } \\
\text { weight) }\end{array}$ & $\begin{array}{l}\text { Field strength } \\
\text { KGauss }\end{array}$ & $\begin{array}{c}\text { Magnetic } \\
\text { susceptibility } \\
\text { (cm } 10^{-6} \mathrm{cgs} \\
\text { units) }\end{array}$ & $\begin{array}{l}\text { Magnetic } \\
\text { moments } \\
\text { meff (B.M) }\end{array}$ & $\begin{array}{c}\text { Elemental analysis (\%) } \\
\text { found (calcd) }\end{array}$ \\
\hline $\begin{array}{l}\text { CoMePhlmPcO } \\
(86 \%) \\
\text { Dark green }\end{array}$ & $\begin{array}{c}\mathrm{C}_{96} \mathrm{H}_{72} \mathrm{~N}_{16} \mathrm{O}_{8} \mathrm{Co} \\
-(634.9)\end{array}$ & $\begin{array}{c}2.2 \\
2.66 \\
3.1 \\
3.58 \\
4.01\end{array}$ & $\begin{array}{l}+2642.28 \\
+2439.08 \\
+2103.52 \\
+1937.02 \\
+1804.08\end{array}$ & $\begin{array}{l}2.85 \\
2.75 \\
2.64 \\
2.51 \\
2.4\end{array}$ & $\begin{array}{c}\text { C, 70.28; (70.46) } \\
\text { H, 4.35; (4.40) } \\
\text { N, 13.65; (13.70) } \\
\text { Co, 3.56; (3.60) }\end{array}$ \\
\hline $\begin{array}{l}\text { CuMePhlmPcO } \\
(85 \%) \\
\text { Dark green }\end{array}$ & $\begin{array}{c}\mathrm{C}_{96} \mathrm{H}_{72} \mathrm{~N}_{16} \mathrm{O}_{8} \mathrm{Cu} \\
(1639.5)\end{array}$ & $\begin{array}{c}2.2 \\
2.66 \\
3.1 \\
3.58 \\
4.01\end{array}$ & $\begin{array}{l}+2610.1 \\
+2471.16 \\
+2125.54 \\
+1939.46 \\
+1825.62\end{array}$ & $\begin{array}{l}2.78 \\
2.65 \\
2.57 \\
2.47 \\
2.42\end{array}$ & $\begin{array}{c}\text { C, 70.13; (70.26) } \\
\text { H, 4.24; (4.39) } \\
\text { N, 13.51; (13.60) } \\
\text { Co, 3.72; (3.87) }\end{array}$ \\
\hline $\begin{array}{l}\text { NiMePhlmPcO } \\
(79 \%) \\
\text { Dark Green }\end{array}$ & $\begin{array}{l}\mathrm{C}_{96} \mathrm{H}_{72} \mathrm{~N}_{16} \mathrm{O}_{8} \mathrm{Ni} \\
(1634.7)\end{array}$ & 2.66 & -766.81 & - & $\begin{array}{c}\text { C, 70.25; (70.47) } \\
\text { H, 4.23; (4.40) } \\
\text { N, 13.62; (13.70) } \\
\text { Co, 3.49; (3.59) }\end{array}$ \\
\hline $\begin{array}{l}\text { ZnMePhlmPcO } \\
(74 \%) \\
\text { Green with brown ting }\end{array}$ & $\begin{array}{l}\mathrm{C}_{96} \underset{(1641.4)}{\mathrm{H}_{72} \mathrm{~N}_{16} \mathrm{O}_{8} \mathrm{Zn}} \\
\quad \mathrm{g}\end{array}$ & 2.66 & -849 & - & $\begin{array}{c}\text { C, 70.04; (70.18) } \\
\text { H, 4.13; (4.38) } \\
\text { N, 13.42; (13.6) } \\
\text { Zn, 4.72; (4.98) }\end{array}$ \\
\hline
\end{tabular}


Q-band is due to M-MePhImPcO's was observed to be shifted to higher wavelength range. The peaks are observed in the wavelength range $577-593 \mathrm{~nm}$ for Cu-MePhImPcO, Co-MePhImPcO, Ni$\mathrm{MePhImPcO}$, and $\mathrm{Zn}-\mathrm{MePhImPcO}$ which is accounted for aggregation of complexes in the solvent. For all M-MePhImPcO's a band was observed in the wavelength range of $214-226 \mathrm{~nm}$ suggested C-band of the phthalocyanine complexes.

\section{Infrared absorption spectra}

Infrared spectra were data recorded the substituted metal (II) octa-methoxyphenylimino phthalocyaninesa complex was recorded in $\mathrm{KBr}$ pellets and the reported results were presented in Table 2. In the range at $3424-3451 \mathrm{~cm}^{-1} \mathrm{a}$ broad absorption band were observed for all complexes and assigned to the $\mathrm{H}$ - bonding formed between nitrogen atom of the phthalocyanine molecules, hydrogen atom of moisture absorbed on $\mathrm{KBr}$ pellets during pelletization. The peak observed in the range $2362-2364 \mathrm{~cm}^{-1}$ is due to $\mathrm{C}-\mathrm{H}$ stretching vibration on the periphery of the phthalocyanine moiety. The sharp peak at $1628-1634 \mathrm{~cm}^{-1}$ is assigned to $\mathrm{C}=\mathrm{N}$ of imine group and the peaks in the 1380-1387 $\mathrm{cm}^{-1}$ is due to $\mathrm{C}-\mathrm{N}$ aromatic stretching frequency. The bands at 1045-1119, and 741-772 $\mathrm{cm}^{-1}$ may be observed to the various phthalocyanines skeletal vibration.

\section{Magnetic Susceptibility}

The magnetic susceptibility and magnetic moments values of square planner M-MePhImPcO's were investigated in the solid state over a range of 2.20-4.45K Gauss and summary of the results were in Table. 1. The values reported are the average of three independent determinations. The magnetic susceptibility were studies revealed that $\mathrm{CuMePhImPcO}$ and CoMePhlmPcO are paramagnetic and NiMePhImPcO and $\mathrm{ZnMePhImPcO}$ are diamagnetic complexes.

The observed magnetic moments for CuMePhImPcO and CoMePhImPcO are higher than the expected only spin value corresponding to one unpaired electron (1.73BM), mixing of higher energy degenerate states with ground state orbital

Table. 2: Electronic, IR and powder XRD data of metal (II) octamethoxyphenylimino phthalocyanines

\begin{tabular}{|c|c|c|c|c|}
\hline Complex & $\begin{array}{c}\text { UV-visible absorption } \\
\text { I nm (logî) }\end{array}$ & $\begin{array}{l}\text { IR-Spectral } \\
\text { Data }\left(\mathrm{cm}^{-1}\right)\end{array}$ & $\begin{array}{l}\text { Powder. XRD data } \\
2 q \text { angle (d } \AA \text { ) }\end{array}$ & $\begin{array}{c}\text { Relative } \\
\text { intensity (\%) }\end{array}$ \\
\hline \multirow{5}{*}{ CoMePhlmPcO } & $218(4.82)$ & $741,1045,1170$ & 27.77, (3.49) & 100 \\
\hline & $260(4.80)$ & $1382,1634,1711$ & $28.93,(3.11)$ & 79.36 \\
\hline & $335(5.42)$ & 2362,3451 & $24.53,(3.40)$ & 49.25 \\
\hline & $593(5.07)$ & & $31.30,(2.72)$ & 31.46 \\
\hline & $749(5.20)$ & & & \\
\hline \multirow[t]{5}{*}{ CuMePhlmPcO } & 214 (4.92). & 772,1090, 1387, & 45.52, (2.82) & 100 \\
\hline & 265 (4.79) & $1634,1718,2362$ & $31.72,(2.84)$ & 80.28 \\
\hline & 337 (5.43) & 3442. & $43.77,(2.73)$ & 52.44 \\
\hline & $584(5.02)$ & & $25.96,(3.45)$ & 34.27 \\
\hline & $747(5.14)$ & & & \\
\hline \multirow{6}{*}{ NiMePhImPcO } & $226(4.90)$ & $759,1119,1363$ & 27.93, (3.74) & 100 \\
\hline & 257 (4.63) & 1401, 1628, 2223, & $28.82,(3.11)$ & 79.24 \\
\hline & $328(5.06)$ & 2362,3424 & $23.25,(3.45)$ & 44.32 \\
\hline & $582(4.44)$ & & $42.76,(2.83)$ & 29.54 \\
\hline & $726(4.61)$ & & & \\
\hline & $219(5.58)$ & & & \\
\hline \multirow[t]{4}{*}{ ZnMePhImPcO } & $251(5.46)$ & $769,1121,1380$ & 27.94, (3.57) & 100 \\
\hline & $327(5.41)$ & 1632 ,2325, 2364, & $28.88,(3.03)$ & 80.81 \\
\hline & 577 (5.39) & 3441. & $42.96,(2.75)$ & 50.24 \\
\hline & $728(5.04)$ & & $20.52,(4.37)$ & 35.91 \\
\hline
\end{tabular}


and intermolecular co-operative effects. The higher magnetic moment then spin only value is due to the orbital contribution to $\mu_{\text {eff }}$ which may arise as a result of mixing of ground state orbitals $\left(\mathrm{b}_{2 \mathrm{~g}}\right)^{2},\left(\mathrm{e}_{\mathrm{g}}\right)^{4}$, and $\left(\mathrm{a}_{1 \mathrm{~g}}\right)^{1}$ with higher orbitally degenerate states $\left(b_{2 g}\right)^{2},\left(e_{g}\right)^{3}$ and $\left(a_{1 g}\right)^{2}$. The orbital contributes is consists of higher at magnetic field then that of higher one evidenced by higher $\mu_{\text {eff }}$ values at lower field strength attributed to intermolecular magnetic interaction coupled with magnetic anisotropy of phthalocynanines $\pi$ electronic current as reported in the literature. The crystallographic studies that the metal phthalocyanines of $\mathrm{Cu}, \mathrm{Co}, \mathrm{Ni}$ and $\mathrm{Zn}$ has square planar structure with $D_{4 h}$ symmetry and are isomerphous.

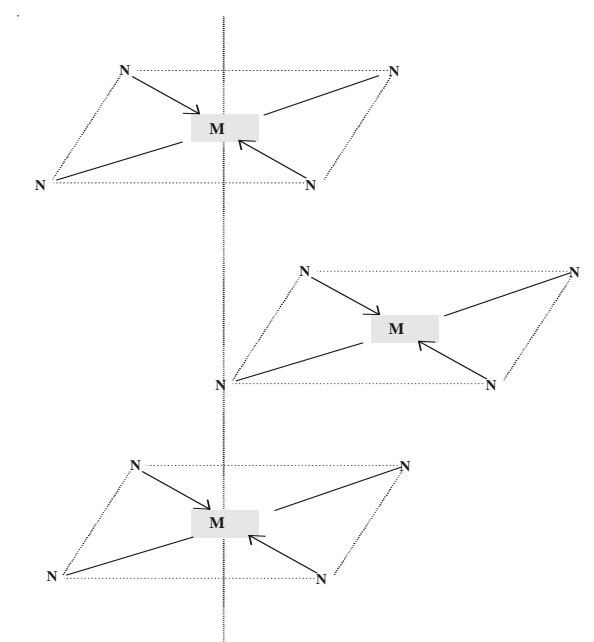

Fig. 2. Probable molecular stacking of metal phthalocyanine crystal, $(\mathrm{M}=\mathrm{Cu}, \mathrm{Co}, \mathrm{Ni}, \mathrm{Zn}$.)

$\mathrm{N}=$ azamethanic atom of phthalocyanine.

The molecular plan is approximate normal to a-b plane and molecules were stacked along the short b-axis. The molecular planes are inclined to the a-c axis at an angle of $45^{\circ}$. Thus the complexes stacked in column with $\mathrm{N}$-atoms above and below on every metal atom (Fig.2) Hence the nearest neighbouring molecule along the $b$-axis contributes $\mathrm{N}$-atom at the interplanar distance $3.8 \mathrm{~A}^{\circ}$.

The overlapping of two neighboring molecules depends on the crystal modification. The XRD data reveals that the M-MePhImPcO's as in $\beta$ form. The substituted metal (II) of one of the phthalocyanine overlaps with $\mathrm{N}$-atom of azamethine atom of the other metal phthalocyanine molecule.

\section{Powder XRD}

The spectra of M-MePhImPcO's in the range of $2 \theta$ angles $6-70^{\circ}$ showed are not identical peaks Table -2. It is observed two peaks. One of the sharp peak at lower angle with maximum intensity and the other peak at higher angle with higher intensity. The inter- planar spacings on these angle gave the following values. Co-MePhImPcO 3.49, $27.97 \AA \AA$; Cu-MePhImPcO 2.82, $45.52 \AA \AA$; NiMePhlmPcO 3.74, $27.93 \AA$ and Zn-MePhImPcO $3.57,27.94 \AA$, clearly indicating the crystanilline nature of the complex. The observed patterns are very much similar to those of the unsubstituted parent phthalocyanines except the broadening of the peaks in the case of M-MePhImPcO's which may be due to the presence of substituents and which seems to play an significant role in the stacking of the substituted metal (II)phthalocyanine derivatives. X-ray diffraction patterns are used only to explain crystallinity qualitatively.

\section{Thermogravimatric and Kinetic Studies}

Thermogravimatric analytical data of octamethoxyphenyliminophthalocyanine complexes both in air and nitrogen atmosphere are summarized in the Table 3 and 4 . It is observed that the decomposition of the above complexes occurs generally in two steps, revealed that the initial weight loss of $2-3 \%$ corresponding to moisture. The first step degradation in air, which takes place in the temperature range of $250-350^{\circ} \mathrm{C}$, may be accounted for the loss of four substituted imine groups. The major weight loss is observed for all the complexes in the second step in the temperature ranges of $350-600^{\circ} \mathrm{C}$ corresponds to the oxidative degradation of remaining four
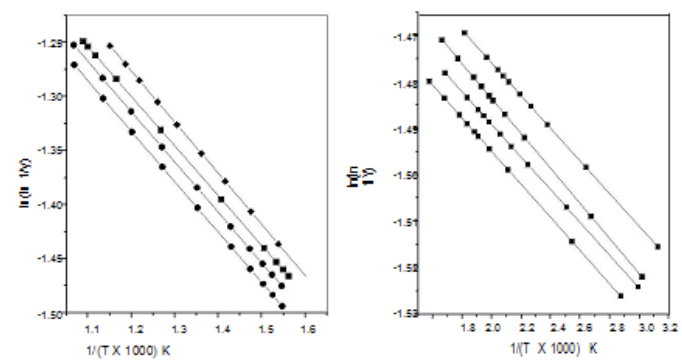

Fig. 3. Plots of $\ln (\operatorname{In} 1 / y)$ versus $1 / T$ for thermal degradation of $(\bullet \bullet \bullet)$ CuMePhlmPcO,

$(\bullet \bullet \bullet)$ CoMePhImPcO, $(\bullet \bullet \bullet \bullet)$ NiMePhImPcO and ( $\square \square \square$ ) ZnMePhImPcO in air. 
Table. 3: TGA data of $\mathrm{Cu}(\mathrm{II}), \mathrm{Co}(\mathrm{II}), \mathrm{Ni}(\mathrm{II})$ and $\mathrm{Zn}$ (II)-octa-methoxyphenylimino phthalocyanines.

\begin{tabular}{lcccc} 
Complex & Temperature of & Mass Loss & Probable mode of & \\
\hline & Decomposition ${ }^{\circ} \mathbf{C}$ & (\%) Found & (\%)Calcd & Fragmentation \\
CuMePhImPcO & $250-350$ & 29.83 & 30.05 & 8-Imino groups \\
\hline $350-600$ & 65.45 & 65.84 & Pc moiety & CoMePhImPcO \\
$250-350$ & 29.81 & 30.17 & 8-Imino groups & \\
& $350-600$ & 65.94 & 65.04 & Pc moiety \\
NiMePhImPcO & $250-350$ & 29.77 & 30.16 & 8-Imino groups \\
& $350-600$ & 65.86 & 65.18 & Pc moiety \\
ZnMePhImPcO & $250-350$ & 29.65 & 30.14 & 8-Imino groups \\
& $350-600$ & 65.53 & 65.14 & Pc moiety \\
\hline
\end{tabular}

Table. 4: Kinetic and thermodynamic parameters of octa-methoxyphenyliminophthalocyanines of $\mathrm{Cu}, \mathrm{Co}, \mathrm{Ni}$ and $\mathrm{Zn}$ in air and inert atmosphere

\begin{tabular}{|c|c|c|c|c|c|c|}
\hline Compounds & & $\begin{array}{l}\text { Activation energy } \mathrm{E}^{0} \\
\mathrm{KJ} / \mathrm{mole}\end{array}$ & $\begin{array}{c}\text { Frequency } \\
\text { factor. } \operatorname{In} \mathrm{A} \text { min }^{-1}\end{array}$ & $\begin{array}{c}\Delta \mathrm{H} \\
\mathrm{KJ} / \mathrm{mole}\end{array}$ & $\begin{array}{l}\Delta \mathrm{S} \\
\mathrm{J} / \mathrm{K}\end{array}$ & $\begin{array}{c}\Delta \mathrm{G} \\
\mathrm{KJ} / \mathrm{mole}\end{array}$ \\
\hline \multirow[t]{4}{*}{ CuMePhImPcO } & I & 5.86 & 6.16 & 2.72 & -165.04 & 62.41 \\
\hline & & -0.74 & -2.02 & $(-1.28)$ & $(-160.03)$ & -61.53 \\
\hline & II & 3.73 & 5.37 & -0.74 & -152.26 & 81.66 \\
\hline & & -1.52 & -5.46 & $(-2.42)$ & $(-149.74)$ & -79.54 \\
\hline \multirow[t]{4}{*}{ CuMePhlmPcO } & I & 0.88 & 6.36 & -1.37 & -176.06 & 74.94 \\
\hline & & -0.67 & -3.38 & $(-1.11)$ & $(-174.11)$ & -74.78 \\
\hline & II & 4.66 & 7.48 & 2.87 & -143.93 & 79.53 \\
\hline & & -1.25 & -4.65 & $(-1.32)$ & $(-141.97)$ & -77.26 \\
\hline \multirow[t]{4}{*}{ NiMePhlmPcO } & I & 1.44 & 5.22 & -1.24 & -159.63 & 72.87 \\
\hline & & -0.71 & -2.25 & $(-0.78)$ & $(-157.58)$ & -70.56 \\
\hline & II & 5.85 & 4.44 & -0.86 & -149.76 & 81.74 \\
\hline & & -1.53 & -4.83 & $(-0.84)$ & $(-143.64)$ & -80.23 \\
\hline \multirow[t]{4}{*}{ NiMePhImPcO } & I & 1.94 & 3.49 & -0.96 & -175.96 & 75.26 \\
\hline & & -0.67 & -2.38 & $(-1.48)$ & $(-173.35)$ & -74.96 \\
\hline & II & 8.55 & 7.97 & 2.86 & -142.74 & 82.45 \\
\hline & & -5.53 & -6.45 & $(-1.52)$ & $(-140.43)$ & -80.92 \\
\hline
\end{tabular}

(I and II corresponds to the I and II stage of degradation and the values in the parenthesis are for nitrogen atmosphere)

substituted imine groups and phthalocyanine moiety. Analysis of the final charred residue corresponds to the corresponding metal oxides. The thermal decomposition of imino substituted metal phthalocyanine complexes in the nitrogen atmosphere appears to be very slow. For Co-MePhImPcO, $69 \%$ of the complex was found to be decomposed at $700^{\circ} \mathrm{C}$. For Cu-MePhImPcO, $\mathrm{Ni}-\mathrm{MePhImPcO}$ about $55 \%, 54 \%$ and $43 \%$ loss of the mass was observed for $\mathrm{Zn}-\mathrm{MePh} I m \mathrm{PcO}$. Above 
trend conforms the relatively stability of these complexes in the order $\mathrm{Co}-\mathrm{MePh} / \mathrm{mPcO}>\mathrm{Cu}-$ $\mathrm{MePhImPcO}>\mathrm{Ni}-\mathrm{MePhImPcO}>\mathrm{Zn}-\mathrm{MePhlmPcO}$. DTA results revealed that all degradation steps are exothermic in nature. Kinetic and thermodynamic parameters of the title complexes have been evaluated by Boride's method.

Plot of $\ln (\ln 1 / y)$ versus $1 / T$ (where $y$ is the fraction of the complex not decomposed) were developed for the decomposition segment where loss of functional groups occur. From the plots, the energy ogactivation(Ea) and frequency factor $(\operatorname{In} \mathrm{A})$ were evaluated. Enthalpy $(\Delta \mathrm{H})$, Entropy $(\Delta S)$ and free energy $(\Delta)$ have been computed using standard equation in Table 4.

\section{CONCLUSION}

A simple and convenient method has been optimized for the synthesis of pigments -octa methoxyphenylimino phthalocyanines of $\mathrm{Cu}$ (II), Co (II), $\mathrm{Ni}$ (II) and Zn (II). Magnetic susceptibility studies revealed the paramagnetic behavior of $\mathrm{CU}$ (II) and Co (II) octamethoxyphenyliminophthalocyanine derivatives and the variation of magnetic moments with magnetic field indicated the presence of intermolecular cooperative effect. Thermogravimatric analysis of the complexes in an inert atmosphere revealed the stability in the order CuMePhImPcO >CoMePhImPcO > NiMePhlmPcO > ZnMePhlmPcO.

\section{ACKNOWLEDGEMENTS}

The authors are thankful to the HOD, Department of Chemistry, MIT, Manipal for providing the basic laboratory facilities; thanks are also due to Prof. A.M.A. Khader, MangaloreUniversity, Prof. M.A. Pasha, Bangalore University, and Mr.Harikrishana Bhatt from RRL, Trivandrum for recording spectraldata.

\section{REFERENCES}

1. Achar, B.N.;J.M. Bhandari, J.M. Synth. React. Inorg. Metal.-Org. Chem. 1993, 23(1), 133- 148

2. Achar, B.N.; G.M. Fohlen,;Parker, J.A,; Keshavayya, J.Polyhedron. 1987, 6 (6), 1463-1467

3. Broido, A. J. PolymSci, 1969, 2 (7), 1761-1773

4. Gregory, P.J. Porphyrins and Phthalocyanines. 2000, 3(4), 432

5. Hanack, M,;Lang, M. Adv. Mater. 1994, 6, 819-833

6. Leznoff, C.C,;Lever, A. B. P. Phthalocyanines, Properties and Applications, vols. 1-4, VCH, New York. 1996

7. Moinuddin Khan, M.H,;Fasiulla,; Harish, M. N.K,; Keshavayya, J,;Venugopla Reddy, K.R. J. Coordination. Chem. 2007, 60(12), 1225-1276

8. Selwood, P.Magneto chemistry, Interscience, New York. 1956

9. Somashekarappa, M.P,;Keshavayya, J. Synth React Inorg Met-Org.Chem. 1999, 29(5), 767-783
10. Venkataraman, K. The Chemistry of Synthetic Dyes, Academic Press, New York.1952, 2.

11. Venugopala Reddy, K.R,;J. Keshavayya, J.Synth React Inorg Met-Org Chem. 2002, 32 (7), 1235-1244

12. Venugopala Reddy, K.R,;Keshavayya, J. Turk. J.Chem.2002, 26(4), 573-580

13. Venugopla Reddy, K.R,; M.N.K.Harish, M. N. K,; Fasiulla, Moinuddin Khan, M/ $\mathrm{H}$,; Keshavayya, J. J. Fluorine Chem. 2007, 128, 1019-1025.

14. Wright, J.D. Prog Surf. Sci, 1989, 31(1).

15. Someshakarappa, M.P,; Keshavayya.J. Spectrochemica Acta. 2003, 59-67.

16. Venugopala Reddy, K.R,;Keshavayya, J. Dyes and Pigments. 2002, 187-194.

17. Moinuddin Khan, M.H,;Harish, Keshavayya, J,;Venugopla Reddy, K.R. J. Coordination. Chem. 2009, 62(5), 854-862. 